\section{Honing our clinical awareness of sexual abuse}

In "A longitudinal study of sexuality and gynecologic health in abused women,"appearing in this issue, J. Dudley Chapman, DO, illustrates the potentially profound, long-lasting, and devastating effects of sexual violence (unwanted sexual contact with or without intercourse). While statistics are somewhat imprecise because of underreporting, studies indicate that as many as one in four women has experienced some form of sexual violence. We know even less concerning the potential long-term effects of such violence. However, Dr Chapman raises issues that should heighten the clinical awareness of all physicians who treat women.

See Dr Chapman's study, beginning on page 619.

The effects of sexual abuse can be far-reaching. This comes as no surprise to osteopathic physicians with our view of the whole person and our understanding of physiology. In a recent issue of American Journal of Psychiatry, James Morrison, MD, relates somatization disorders to childhood molestation. Similarly, Dr Chapman demonstrates the relationship between sexual violence and physical disorders such as abdominal or pelvic pain, vaginismus, and leukorrhea. In diagnosing these physical problems, physicians perform numerous procedures; many prove unnecessary in the long run and only create their own morbidity without ameliorating the underlying cause.

This last point reminds us of the relationship between body and mind and the nervous system's integrating role. As Irvin Korr, $\mathrm{PhD}$, has so eloquently stated, the body is a unit in which all parts function in the context of the entire organism. Disease is a reaction of the organism as a whole. Abnormal structure, or function (or both) in one part exerts abnormal influence on other parts, and, therefore, on the total body economy.

Consequently, all clinicians must be aware of the three P's when treating patients with gynecologic problems: Physical changes, procedures, and panic. As Dr Chapman notes, physical changes may take such forms as pain, vaginismus, or leukorrhea. Diagnostic procedures help rule out serious disease. We should always search for the primary cause of the symptoms that we are evaluating. However, if the patient has had multiple gynecologic procedures and symptoms persist, then sexual trauma should be considered the primary cause.

I define panic in this instance as anything from simple anxiety in sexual behavior to sheer panic at the thought of sexual contact. If such panic characteristics are present, sexual violence should be suspected as the primary cause for gynecologic abnormalities. Until this primary problem is addressed, the secondary symptoms will persist. At the same time, caregivers need to treat the abuser as well.

Violence destroys human relationships and the fabric of society. We must sharpen our awareness of the violence that we do to ourselves, our partners and children, and society at large. Our task is to discover and teach nonviolent ways to interact with each other and our environment. Human progress and survival depend on it.

JEFFREY J. PATTERSON, DO

Madison, Wis

1. Morrison J: Childhood sexual histories of women with somatization disorder. Am J Psychiatry 1989;146:239-241.

2. Gelles RJ, Straus M: Intimate Violence: The Definitive Study of the Causes and Consequences of Abuse in the American Family. New York, Simon and Schuster, 1988.

3. Russell D: The Secret Trauma: Incest in the Lives of Girls and Women. New York, Basic Books, Inc, 1987.

\section{Tuberculosis remains a formidable adversary}

Despite receiving little media coverage recently, tuberculosis (TB) persists as a detriment to health in this country. More than 20,000 new cases are reported annually to the Centers for Disease Control (CDC). While chemotherapy and newer treatment regimens were responsible for a steady decline in newly diagnosed TB cases from 1950 to 1985 , the trend has since remained constant.

Several contributing factors explain this disappointing finding: an increase in AIDS-related cases; increased numbers of homeless; and an influx of immigrants emigrating from countries where TB is endemic.

(continued on page 618) 